\title{
ANÁLISIS HISTOLÓGICO DE IMPLANTES DE APATITA CARBONATADA POROSA DE SÍNTESIS SECA Y CÉLULAS DE MÉDULA ÓSEA DE PORCINO
}

\author{
Estaban Camilo Rodríguez Estupiñán ${ }^{1}$, Luz Dayanis Pinzón Garzón ${ }^{1}$, Diana Sofía Garzón Romero,

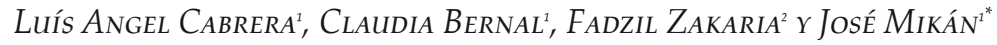 \\ ${ }^{1}$ Grupo Biotecnología en Salud, Laboratorio de Investigaciones, Facultad de Medicina, Universidad Militar \\ Nueva Granada, Bogotá, Colombia. ${ }^{2}$ Biomaterials Programme, Advanced Materials Research Centre (AMREC), \\ SIRIM Berhad, Lot 34, Jalan Hi-Tech 2/3, Kulim Hi-Tech Park, 09000 Kulim, Kedah, Malaysia.
}

\begin{abstract}
Resumen
La apatita carbonatada (CAp) constituye uno de los principales componentes del tejido óseo. Después de sintetizar CAp por precipitación de soluciones acuosas y por reacción del estado sólido, se tomó material poroso de CAp de síntesis seca previamente embebido con células de medula ósea, y se implantó subcutáneamente y en defectos óseos creados en porcinos. En este artículo se muestra la descripción y el análisis de los cortes histológicos de muestras del material implantado. Los resultados obtenidos indicaron que el material no genera rechazo, es reabsorbido por actividad de los osteoclastos del individuo receptor y es reemplazado por tejido óseo neoformado. El tipo de osificación con el que se regenera el tejido óseo en las perforaciones creadas y reemplazadas y no reemplazadas con CAp, es la osificación membranosa la cual se describe. Las diferencias cuantitativas observadas en los controles y tratamientos respecto del área total del material indican su alta biodegradación, aparentemente explicable por una mayor actividad osteoclástica y/o una respuesta de asimilación mejorada por la presencia de células potencialmente osteogénicas del propio individuo. Esta hipótesis se refuerza por el mayor número de vasos sanguíneos encontrados en los implantes subcutáneos previamente embebidos con células madre de la médula ósea. Según los criterios evaluados, CAp poroso de síntesis seca presenta excelente biocompatibilidad, osteoinducción y osteoconducción, características que se potencian cuando el material es pre-embebido con células de médula ósea.
\end{abstract}

Palabras clave: reacción del estado sólido, apatita carbonatada, células osteoprogenitoras, material de reemplazo óseo.

\section{HISTOLOGICAL ANALYSIS OF IMPLANTED PORUS CARBONATED APATITE OF DRY SYNTHESIS EMBEDDED WITH PORCINE BONE MARROW CELLS}

\begin{abstract}
Carbonated apatite (CAp) constitutes one of the principal inorganic components of the osseous tissue. After synthetising of CAp by reaction of the solid state, the ceramic was treated with porcine bone marrow progenitors and then implanted subcutaneously and in created osseous defects. This article shows the description and analysis of histological samples. Results indicated that the material does not
\end{abstract}

* Correspondencia: José Mikán jose.mikan@unimilitar.edu.co. Dirección Correspondencia: Laboratorio de investigaciones, Facultad de Medicina, Universidad Militar Nueva Granada, Tr. 3a \#49-00, Bogotá, Colombia.

Recibido: Enero 29 de 2010 Aceptado: Mayo 5 de 2010. 
generate rejection; it is re-absorbed by the recipient's osteoclasts activity and then is replaced by biologically synthesised bone. Membranous ossification is described to be responsible for the regeneration of osseous tissue in artificially created defects, with or without being filled with CAp. The quantitative differences between controls and treatments in respect of the total area covered by the material indicate its high biodegradability, probably due to a major osteoclastic activity and/or an improved assimilative response, given the presence of potentially osteogenic cells of the own individual. This hypothesis is reinforced by the observation of more blood vessels in subcutaneous implants previously treated with bone marrow cells. According to the evaluated criteria, porous CAp of dry synthesis shows excellent biocompatibility, osteoinductivity and osteoconductivity, characteristics that are promoted when the material is pre-treated with osteoprogenitors from the bone marrow.

Keywords: solid state reaction, carbonated apatite, osteoprogenitor cells, bone substitutes

\title{
ANÁLISE HISTOLÓGICA DE IMPLANTES DE APATITA CARBONATADA POROSA DE SÍNTESE SECA E CÉLULAS DA MEDULA ÓSSEA DE SUÍNOS
}

\begin{abstract}
Resumo
A apatita carbonatada $\left(\mathrm{CA}_{\mathrm{p}}\right)$ é um componente importante do tecido ósseo. Depois de sintetizar $\mathrm{CA}_{\mathrm{p}}$ por precipitação a partir de soluções aquosas e reação em estado sólido, foi colhido material poroso de $\mathrm{CA}_{\mathrm{p}}$ de síntese seca previamente embebidas com células da medula óssea, e foi introduzida no tecido subcutâneo e em defeitos ósseos criados em suínos. Este artígo mostra a descrição e a análise dos cortes histológicos de amostras do material implantado. Os resultados obtidos indicaram que este não gera rejeiçao, é reabsorvido pela atividade dos osteoclastos do receptor individual e é substituído por tecido ósseo neoformado. $\mathrm{O}$ tipo de ossificação com que é regenerada o tecido óssea nas perfurações criados e substituído e não substituído com $\mathrm{CA}_{\mathrm{p}}$ é a ossificação membranosa que se descreve. As diferenças quantitativas observadas nos controles e tratamentos ao respeito da área total do material indicam sua alta biodegradação, aparentemente explicável por uma maior atividade osteoclástica e/o uma resposta de assimilação melhorada pela presença de células potencialmente osteogénicas do própio individuo. Esta hipótese é reforçada pelo maior número de vasos sanguíneos encontrados nos implantes subcutáneos previamente embebidas com células madre da medula óssea. Segundo os criterios de avaliação, $\mathrm{CA}_{\mathrm{p}}$ poroso de síntese seca mostra excelente biocompatibilidade, osteoindução e osteocondução, características que aumentam quando o material é pré-embebida com células da médula óssea.
\end{abstract}

Palabras-chaves: reação de estado sólido, apatita carbonatada, células osteoprogenitoras, material de substituição óssea

\section{Introducción}

La reparación, corrección y manejo de defectos óseos usando autoinjertos y aloinjertos ha venido en aumento en los últimos años; sin embargo, estos tratamientos pueden conllevar efectos deletéreos para el paciente que no permiten su correcta recuperación e inciden en su calidad de vida (1); a esto se suma una larga lista de contraindicaciones que implica grandes retos para el equipo tratante (2, 3). El desarrollo y uso de bioma- teriales se ha planteado como una buena alternativa en la solución de algunos de estos inconvenientes, con la idea que reemplacen, aumenten o soporten tejidos u órganos. En los últimos 30 años los materiales biocompatibles han tenido gran auge para su utilización en los humanos, sobre todo los materiales para prótesis óseas y dentales $(4,5,6)$.

Las características que deben tener los materiales de reemplazo óseo son la osteoinducción, la osteocon- 
ducción y la biocompatibilidad. La osteoinducción se refiere a la capacidad de una sustancia de inducir el crecimiento óseo, mientras la osteoconducción se refiere a la capacidad de mantener el crecimiento óseo ya iniciado (4), y la biocompatibilidad se define como la capacidad del material para aceptar células competentes y permitir su desarrollo (5). Los principales materiales de reemplazo óseo que se han venido desarrollando durante los últimos diez años incluyen los polímeros sólidos, coral natural, hidroxiapatita, fosfato $\beta$ - tri-calcio, membranas de colágeno entre otros, obteniéndose resultados prometedores al haberse demostrado que aceleran la regeneración ósea $(6,7,8,9)$.

La CAp es uno de los principales componentes inorgánicos de la dentina y el hueso y cumple un importante papel en el metabolismo óseo facilitando la tasa de resorción $(9,10)$. El carbonato constituye entre el 2 al $8 \%$ del peso de la hidroxiapatita carbonatada, reemplazando el $\mathrm{OH}$ (tipo A) y/o el fosfato (tipo B) dentro del cristal. Tanto el tipo A como el B hacen parte del hueso natural encontrándose que el último predomina en el hueso humano joven y el primero se incrementa con la edad (11).

El objetivo de la ingeniería de tejidos es desarrollar materiales híbridos compuestos de sustratos sintéticos y células tejido específicas; en el caso del reemplazo óseo, las células mesenquimales cumplen una función esencial en la reparación ósea, que es su migración hacia sitios específicos en los huesos que han sufrido traumas, fracturas, necrosis o inflamación, para encargarse de la reparación tisular diferenciándose en células de tejido conectivo (12). Por estas razones desde hace varios años, en nuestros trabajos se han utilizado como potenciadoras de las funciones de los materiales de reemplazo óseo; también se ha hecho la síntesis de CAp por síntesis húmeda y por reacción del estado sólido y se ha utilizado el cultivo de células osteoprogenitoras de porcino para evaluar la citotoxicidad, genotoxicidad y biocompatibilidad del material sintetizado $(13,14,15)$. En este artículo se describen y analizan cortes histológicos de muestras de material poroso de CAp de síntesis seca, embebido con células de medula ósea de porcino y sometido a un proceso experimental in vivo de ocho semanas de duración, durante el cual se realizaron implantaciones subcutáneas $e$ implantaciones en defectos óseos creados y luego se evaluaron las características de biocompatibilidad, osteoinducción y osteoconducción de CAp poroso pre-embebido con células de médula ósea.

\section{Materiales y métodos}

\section{Tratamiento in vitro de las piezas de CAp embebidas con células de médula ósea}

Se fabricaron piezas cilíndricas (diámetro $\mathrm{x}$ altura $=$ $1 \mathrm{x} 0,5 \mathrm{~cm}$ ) de material poroso de CAp, sintetizado por el método de reacción del estado sólido (16). Primero, se lavaron los cilindros con una solución de ácido acético $5 \mathrm{mM}$ por 24 horas para neutralizar residuos de la reacción, seguido de enjuagues con agua destilada hasta obtener $\mathrm{pH} 7,2-7,4$. Posteriormente, el material se esterilizó en autoclave y se hizo reaccionar a $37^{\circ} \mathrm{C}$ por cinco días con solución de fluido corporal simulado (SBF) para facilitar la deposición de cristales amorfos (17). Finalmente, las piezas se lavaron con agua destilada estéril y se colocaron en placas de cultivo de poliestireno de 24 pozos ( $1,75 \mathrm{~cm}^{2} /$ pozo). Los pozos con el material, se inocularon con una suspensión de $1 \times 10^{3}$ células extraídas de médula ósea de cada porcino $(\mathrm{CM})$, siguiendo las metodologías de trabajos previos (15). Las piezas a ser implantadas se dividieron en dos tratamientos: subcutáneo (SC) y reemplazo óseo (OS); el control recibió el mismo tratamiento previo, excepto la inoculación de células.

Modelo in vivo para evaluar osteoconducción, osteoinducción y biocompatibilidad del material poroso

Se tomaron cuatro cerdos de raza PigxLandrace, tres machos y una hembra, de cuatro meses de edad y peso aproximado de $40 \mathrm{~kg}$, a los que se les implantó el material SC y OS en sitios específicos. Basados en el protocolo de la legislación Colombiana para el mantenimiento de animales de experimentación, se hizo el diseño del procedimiento a realizar, el cual fue aprobado por el comité de ética de la Universidad Militar Nueva Granada. El proceso de implantación del material se hizo en tres tiempos correspondientes a las semanas dos, cuatro y ocho. En cada tiempo se indujo anestesia general con inyección intramuscular de zolazepam-tiletamina $(0,5 \mathrm{mg} / \mathrm{kg})$ y se mantuvo con fluotano inhalado. Las incisiones para los implantes en tejido SC se realizaron bajo condiciones de asepsia y antisepsia en distintas localizaciones: región del cuello dorsal, región del dorso, región escapular y región axilar, en las cuales se introdujeron piezas con $\mathrm{CM}$ (grupo SC-CM) y piezas sin células (grupo SC-Cont). Para la implantación de CAp en hueso se realizaron perforaciones de $1 \times 0,5 \mathrm{~cm}$ en las diáfisis de las tibias 
izquierda y derecha, en la lámina neurocraneal del hueso frontal y en el cuerpo de la mandíbula de los porcinos, dejando en cada localización un agujero vacío (grupo OS-Cont) y en el otro se colocaron las piezas de CAp (grupo OS-CM). En la primera cirugía realizada 56 días antes del sacrificio, se implantaron las muestras correspondientes a la octava semana, 28 días después se implantaron las muestras de la cuarta semana, y 14 días despues se implantaron las muestras correspondientes a la segunda semana. Finalmente los animales fueron sacrificados y se extrajeron todas las muestras para análisis histológico.

\section{Preparación histológica}

Las piezas fueron lavadas con PBS y fijadas en una solución de glutaraldehido 3\% en PBS por 24 horas, después se lavaron con PBS y se decalcificaron con una solución de EDTA $12 \%$ pH 7,2 hasta obtener muestras gelatinosas (entre dos y cinco semanas). Las muestras blandas fueron deshidratadas en soluciones de acetona de concentración ascendente, embebidas en parafina y cortadas en secciones de $5 \mu \mathrm{m}$ de grosor. Todos los cortes fueron divididos en dos grupos: uno para la tinción de Hematoxilina-Eosina (HE), como tinción primaria para observar todos los detalles generales de un corte óseo y otro con Tricromico de Masson (TM), para observar la distribución del colágeno en las distintas muestras (18).

\section{Valoración cualitativa}

La valoración histológica fue realizada por tres observadores, y se tuvo en cuenta el tiempo de implantación, la tinción y los distintos tipos celulares encontrados en los grupos SC y OS, haciendo énfasis en la comparación de los cortes control con los del tratamiento.

\section{Valoración cuantitativa}

Se cuantificó el área ocupada por material, el número de vasos sanguíneos y células mesenquimales en las muestras del grupo SC; se eligieron dos placas de cada semana con tinción HE y se observaron por microscopía de luz a magnificación de 100x, con una reglilla cuadrada instalada en el ocular de área $1 \mu^{2}$. De cada placa se observaron seis cortes y de cada corte se observaron diez campos. El análisis se realizó teniendo en cuenta el tiempo de implantación y la comparación entre los grupos control y tratamiento. Se determinó realizar los conteos de la siguiente forma: (i) cuantificar las áreas cubiertas con material en la fila de la mitad de la reglilla (quinta fila de arriba hacia abajo), (ii) contar el número de células mesenquimales en los cuatro cuadrantes las esquinas de la reglilla y (iii) contar los vasos sanguíneos en toda la rejilla.

Para comprobar las diferencias de la cuantificación del área ocupada por el material, el número de células mesenquimales y número de vasos sanguíneos entre las distintas muestras, se utilizó como estimador el intervalo de confianza: $\bar{x} \pm 1.96\left(\frac{\sigma}{\sqrt{n}}\right)$
para una $\mathrm{p}=0,05$ y 1 -alfa $=0,95$.

\section{Resultados}

\section{Implantación subcutánea}

La valoración cualitativa de los cilindros de CAp implantados SC en las diferentes localizaciones permitió determinar cambios de estructura del material y su resorción, así como la determinación de los tipos tisulares que invadieron y se desarrollaron dentro de los poros de las piezas, encontrándose diferencias entre los tratamientos y sus respectivos controles.

\section{Hallazgos Histológicos: Generalidades}

Con la tinción HE se observó material poroso totalmente infiltrado por distintos tipos celulares y con desarrollo de tejido óseo. Se vio que en todos los poros del material analizado, se desarrollaron en el centro del poro capilares sanguíneos. Al rededor de los capilares se observó un infiltrado linfo-monocitario abundante constituido por linfocitos indiferenciados, plasmocitos y macrófagos; en la mayoría de los casos se observó monocitos en los vasos tanto en los de la periferia, como en los de dentro del material. Además de este infiltrado, en dirección hacia el material se encontró una zona de tejido conectivo inmaduro con fibrocitos, fibroblastos y células mesenquimales indiferenciadas, o mesénquima embrionario, pero con fibras de colágeno maduras (19) (Figura 1A). Las áreas ocupadas por cada tejido en los tratamientos variaron con el tiempo de implantación y en relación con el control. En la periferia del material se encontraron células óseas e inmunitarias de diversos tamaños, las cuales se describe en detalle más adelante. Con la tinción de TM igualmente se observó la misma disposición de los tejidos y las células. Se determinó además la distribución del tejido colágeno, compo- 
nente principal de la matriz secretada por osteoblastos (Figura 1B). El colágeno se encontró en su mayoría dentro de la zona del tejido conectivo inmaduro similar al mesénquima embrionario previamente descrito, siendo claramente más abundante en las placas del tratamiento (Figura 1C).

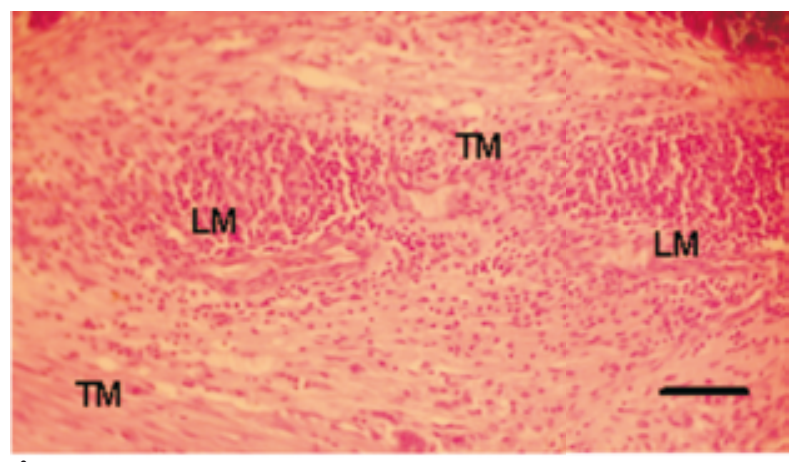

A

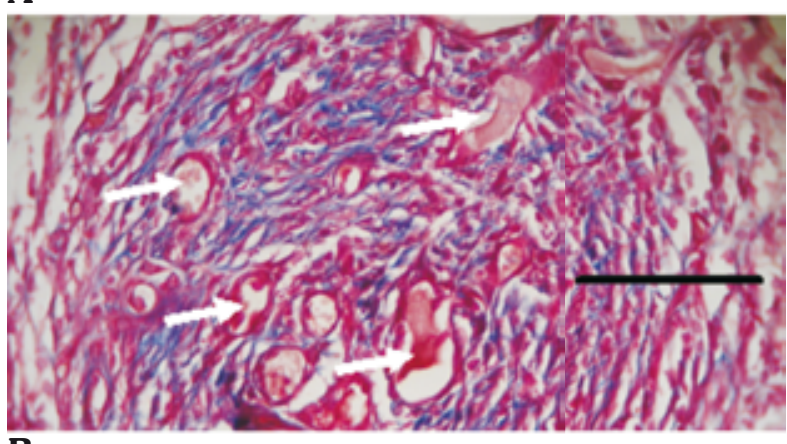

B

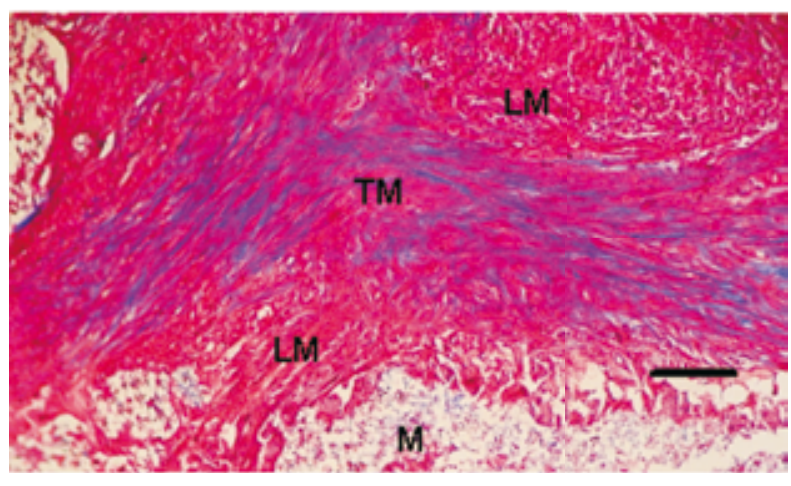

C

FIGURA 1. Cortes de CAp poroso de síntesis seca. A) Cortes a las dos semanas de implantación SC con tinción de EH B) Cortes a las cuatro semanas de implantación SC con tinción TM. Tejido colágeno rodeando capilares (flechas) en un poro del material. C) Cortes a las cuatro semanas de implantación SC con tinción TM mostrando la distribución del tejido colágeno en placa con tratamiento. LM: tejido linfo-monocitario, M: material, TM: área de tejido mesenquimal y tejido fibroso. Barra 100 micrómetros.

\section{Cambios en e CAp y tipos celulares observados}

En todas las muestras con tinción de HE, se observó que el material tomó un color basófilo sin perder su estructura microscópica cristalina (Figura 2A), a excepción del material que se encontró en la periferia de los poros y dentro de células fagocíticas, que no tomó la tinción, mostrando mayor grado la birrefringencia, característica del cristal de hidroxiapatita. También se pudo evidenciar la presencia de células poco eosinófilas dentro del material, a las cuales la mayoría de las veces no se les pudo evidenciar el núcleo característico de los macrófagos (Figura 2B). También se encontraron osteoblastos de morfología cuboide, de tamaño aproximado de 10 micras, con un núcleo heterocromático excéntrico y poco citoplasma unidos a la periferia del material (Figura 2C); algunas veces tienen un halo alrededor del citoplasma correspondiente a la matriz osteoide. Cerca de la periferia del material (borde de la matriz ósea), se encontraron preosteoblastos, de morfología menos cuboide, con núcleo grande y menor cantidad de citoplasma (Figura 2C). Se observaron osteoclastos unidos a la periferia del material, de forma alargada característica o en media luna, de tamaño variable desde 15 hasta 60 micras, siempre multinucleados (de dos a más de 15 núcleos) con citoplasma eosinófilo vacuolado abundante y con borde ondulado, el cual muestra forma plana o cóncava en el segmento de contacto con el material, semejante a las lagunas de Howship (Figura 2D). Se observaron abundantes células mesenquimales indiferenciadas, de morfología fusiforme, gruesas, ligeramente más grandes que los fibroblastos con un tamaño aproximado de 20 micras, con núcleo concéntrico grande heterocromático, poco citoplasma eosinófilo y en algunas ocasiones se evidencian prolongaciones de su citoplasma dándole un aspecto de célula estrellada (Figura 2E). A partir de la segunda semana se observaron células del infiltrado linfo-monocitario. Los linfocitos en su mayoría se observaron como células mononucleares de tamaño aproximado de 9 micras, con núcleo basófilo grande redondo que ocupa la mayor parte de la célula (Figura 2F) y en algunas ocasiones se observaron con una morfología característica de plasmocitos (19).

\section{Valoración cuantitativa}

Se cuantificaron las áreas ocupadas por el material de CAp, el tejido mesenquimal y número de vasos observados en los campos analizados; estos valores se compararon entre las placas control y las del trata- 
Rodríguez E., Pinzón L., Garzón D., Cabrera L., Bernal C., Zakaria F., Mikán J.

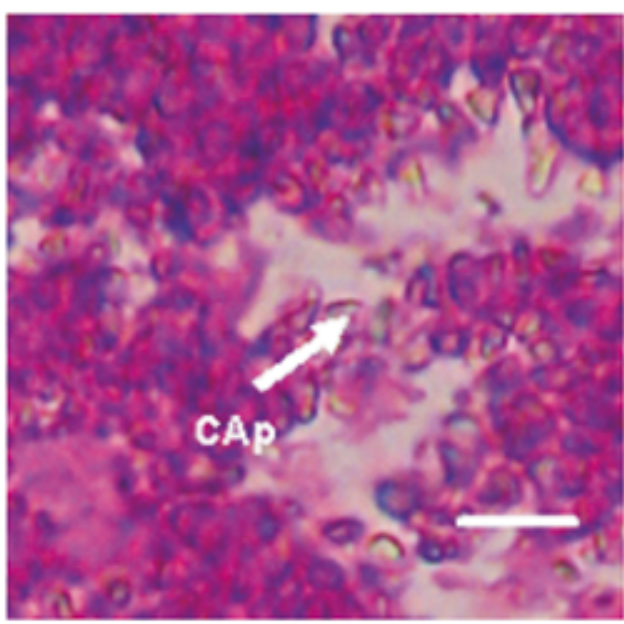

A

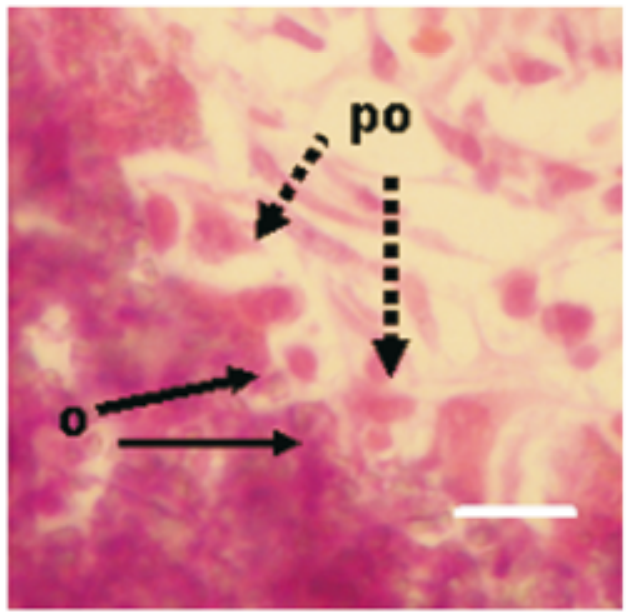

C

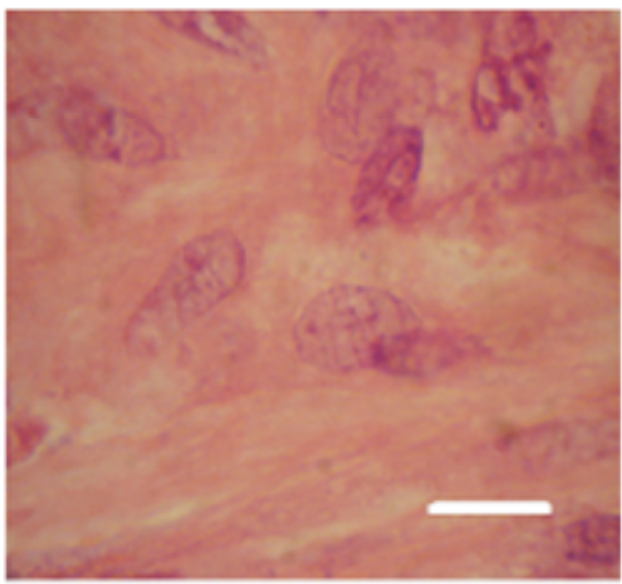

$\mathbf{E}$

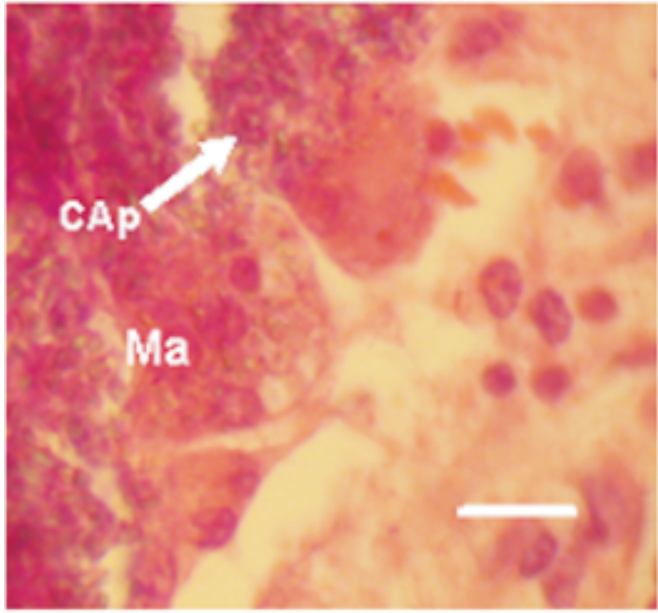

B

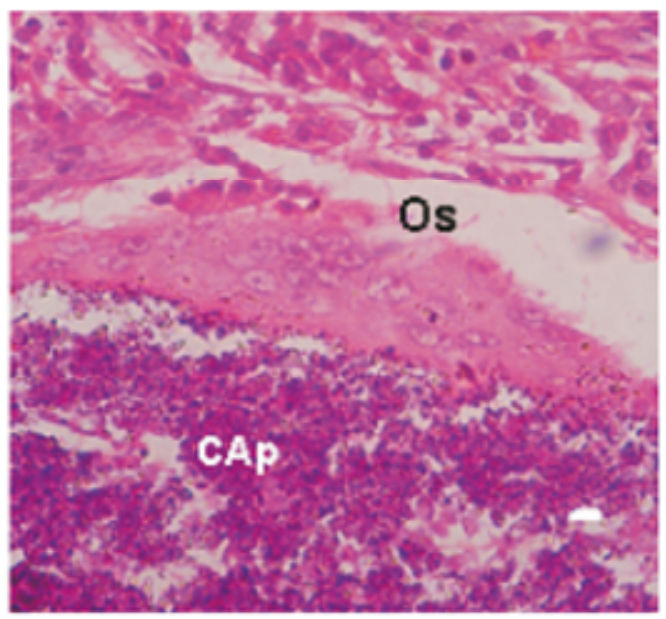

D

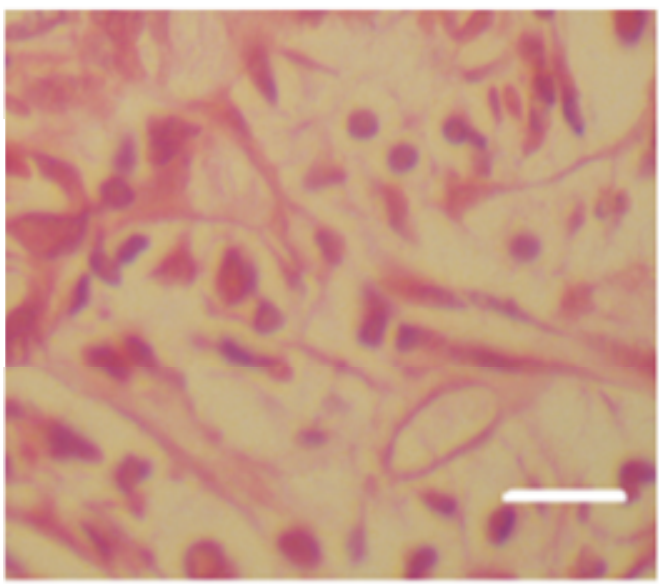

$\mathbf{F}$

FIGURA 2. Cortes de las muestras después de cuatro semanas de implantación SC. Se observa: A) el aspecto moteado del material de CAp y B) macrófagos (Ma) en la periferia de un poro. Cortes de las muestras después de dos semanas de implantación SC. Se observan: C) osteoblastos (o) y preosteoblasto (po), D) un osteoclasto característico (os); E) Células mesenquimales y F) células del infiltrado linfomonocitario. Barra de 10 micrómetros. 
miento. Como lo muestra la Figura 3, el área ocupada por CAp en los controles y los tratamientos disminuyó progresivamente a través del tiempo (control de $75 \%$ a $45 \%$ y tratamiento de $50 \%$ a $40 \%$ ); los valores de los controles se mantuvieron siempre por encima de los valores en las muestras del tratamiento.

Como se muestra en la figura 4, en la segunda semana el número de cuadrículas cubiertas por células mesen- quimales en los tratamientos $(8 \pm 1,01)$ es mayor que la del control $(5 \pm 0,25)$. Sin embargo, a la semana cuarta se observa que la situación se invierte, observándose en las placas control un mayor número de cuadriculas ocupadas por células mesenquimales alcanzando un pico (control 18 $\pm 1,73$, tratamiento14 $\pm 1,01$ ). Finalmente, a la octava semana la cantidad de tejido mesenquimal fue equivalente en controles y tratamientos

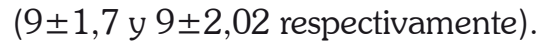

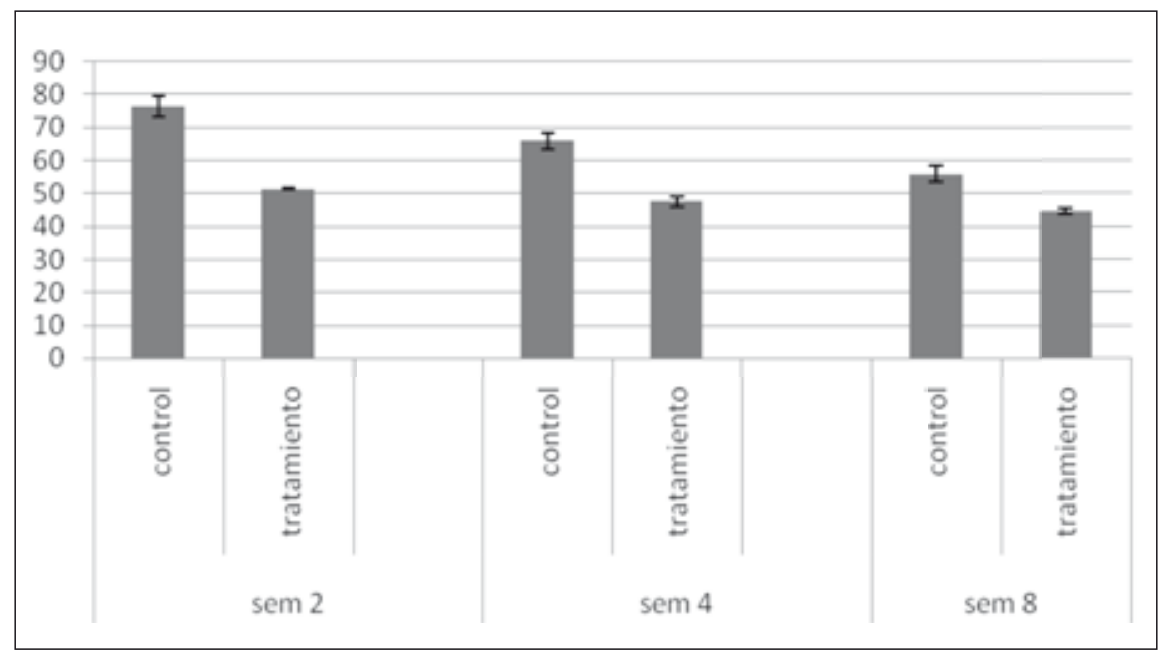

FIGURA 3. Porcentajes de las áreas cubiertas por CAp en los cortes histológicos (ordenadas) vs. semanas del experimento (abscisas). Los histogramas corresponden a los promedios y las barras los intervalos de confianza de 1-alfa = 0,95 en diez campos observados.

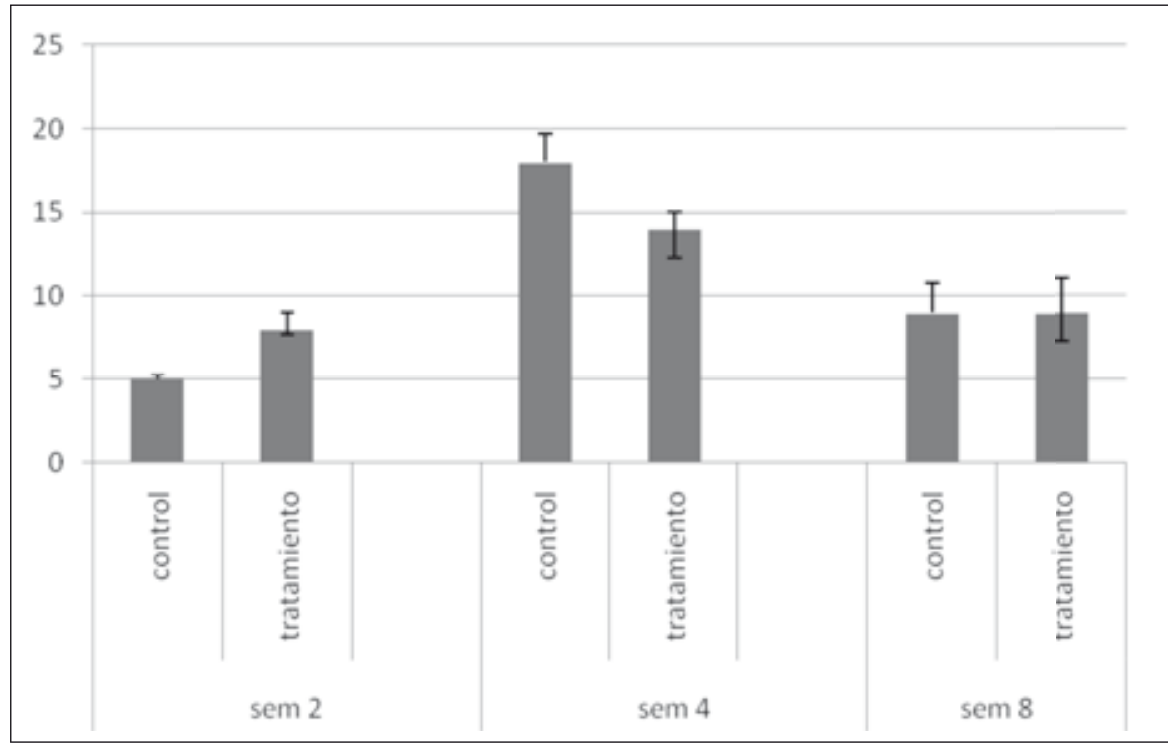

FIGURA 4. Número de cuadriculas cubiertas por células mesenquimales en los cortes histológicos (ordenadas) vs. semanas del experimento (abscisas). Los histogramas corresponden a los promedios y las barras los intervalos de confianza de 1-alfa =0,95 en diez campos observados. 


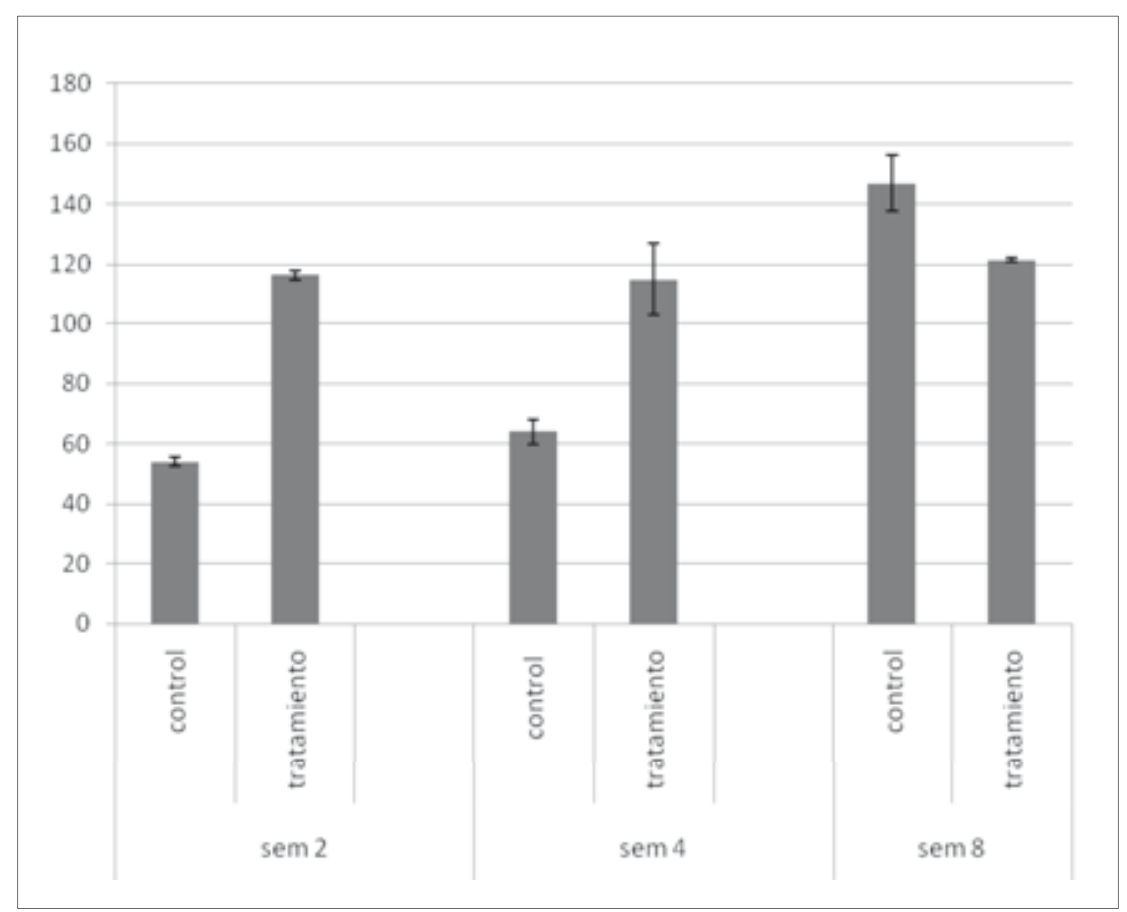

FIGURA 5. Número de vasos sanguíneos observados en los campos del ocular de los cortes histológicos (ordenadas) vs. semanas del experimento (abscisas). Los histogramas corresponden a los promedios y las barras a los intervalos de confianza de 1-alfa $=0,95$ en diez campos observados.

En cuanto a la cantidad de vasos sanguíneos se evidenció un aumento progresivo con el tiempo, con un promedio de 45 a 150 vasos por campo en los controles y de 110 a 120 vasos por campo en los tratamientos (Figura 5). Al comparar el control con los tratamientos se ve un mayor número de vasos en los tratamientos hasta la cuarta semana, cifra que se invierte en la octava semana, cuando los controles muestran un aumento significativamente mayor (140 vs 120 , respectivamente).

\section{Implantación en perforaciones óseas creadas}

La valoración cualitativa de las muestras implantadas en perforaciones óseas creadas (diáfisis de ambas tibias, lamina neurocraneal del hueso frontal y el cuerpo de la mandíbula y sus controles respectivos), permitió determinar las diferencias en los tipos celulares predominantes en cada caso y observar el reemplazo del material por tejido óseo neoformado.

\section{Hallazgos Histológicos: Generalidades}

Los cortes de las lesiones creadas mostraron una clara zona de transición, la cual corresponde a la zona limitante entre el depósito de tejido fibroso dentro del defecto intencionalmente causado y el tejido óseo antiguo. Este tejido conectivo denso irregular se compone principalmente de fibras colágenas con infiltrado principalmente linfocitos, monocitos, fibroblastos y fibrocitos; sin embargo, también alberga células con morfología similar a las mesenquimales indiferenciadas, que predominan cerca al tejido óseo, zona en la cual los capilares sanguíneos son escasos. El hallazgo más importante es que en la zona de transición se observan trabéculas óseas neoformadas pequeñas, rodeadas de osteoblastos y células mesenquimales, sin osteocitos y se encuentran adyacentes al tejido óseo antiguo. Con la tinción TM se destaca la maduración de la matriz en las trabéculas, desde azul intenso rico en colágeno hasta rojo, color característico de la matriz calcificada (Figura 6).

Evolución de las perforaciones óseas creadas con reemplazo de CAp

En los cortes histológicos de las perforaciones óseas con reemplazo de CAp, se pueden observar desde la segunda semana, cristales irregulares fusionados con células multinucleadas irregulares que han crecido entre los cristales refringentes. La zona de transición 


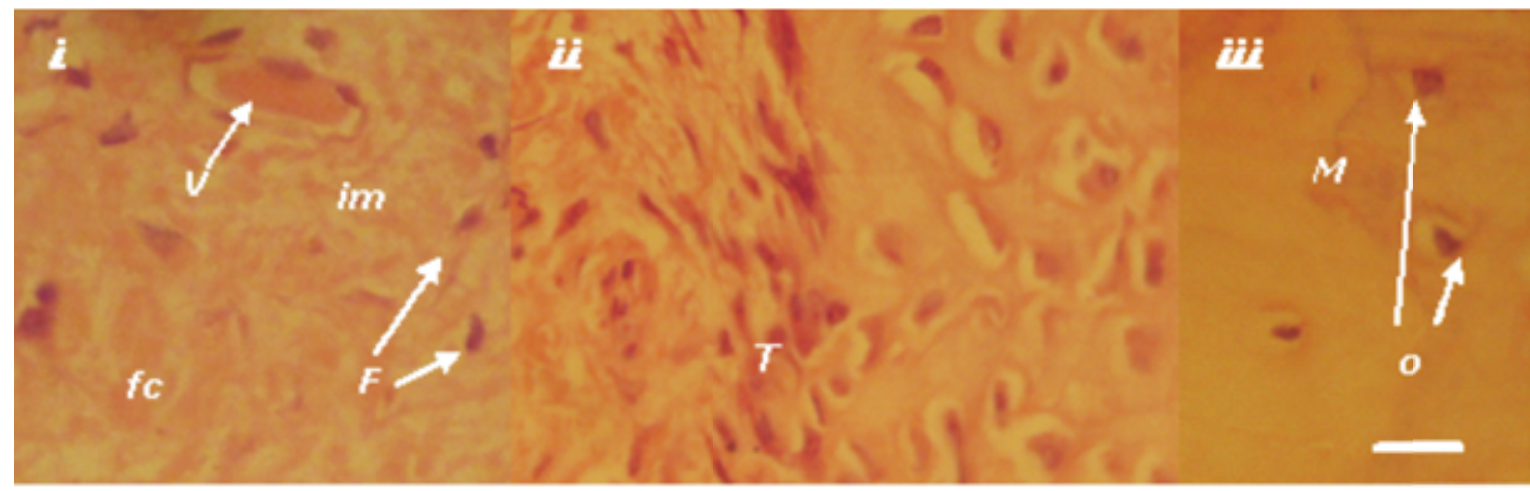

A
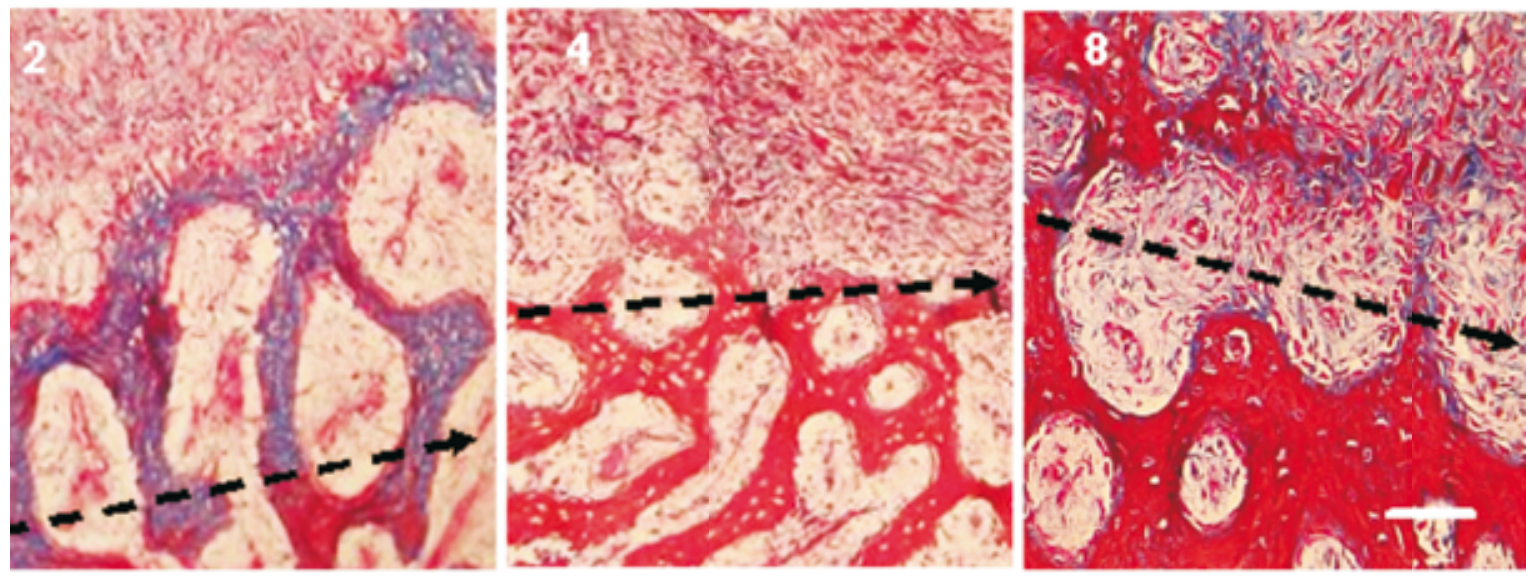

B

FIGURA 6. Análisis microscópico de los cambios en las perforaciones óseas creadas: A) Coloración de H-E donde se observan las diferentes secciones del hueso con el defecto creado: (i) interior del defecto donde se observan fibroblastos ( $F$ ), fibras colágenas ( $f c$ ) e infiltrado linfomonocitario (im), con algunos vasos (v); (ii) Zona limitante donde se observan la formación de trabéculas (t) y (iii) Hueso maduro donde se destacan los osteocitos (o) y la matriz (M). Barra de 10 micrómetros. B) Tinciones con TM que muestra la evolución del defecto óseo a 2, 4 y 8 semanas, donde se destaca la maduración de las trabéculas (azul: abundante colágeno) a matriz calcificada madura (rojo). Las flechas muestran la interfase del hueso y el área de corte. Barra de 100 micrómetros.

es más difusa en las placas tratamiento, donde se destacan trabéculas en formación entre los poros del material, fibroblastos, fibras colágenas e infiltrado linfomonocitario (Figura 7A). Semejante a lo observado en las placas control para las semana 4, se observa la presencia de trabéculas óseas inmaduras ricas en colágeno (distintivo color azul de la tinción TM) entre los gránulos de CAp, los cuales disminuyen en tamaño y son reabsorbidos, mientras que las trabéculas óseas engrosan y tiñen de rojo característico de calcificación hacia la semana octava. Esto implica osificación membranosa, con la presencia de vasos sanguíneos abundantes, tejido colágeno organizado al rededor de los agujeros donde estaban los implantes, ausencia de material, zona de transición no aparente, trabéculas en crecimiento con osteoblastos alrededor y en mayor cantidad trabéculas óseas maduras con osteocitos en su interior. En contraste, en la semana ocho en el control (sin material) aun se observa tejido colágeno organizado al rededor de la interfase del hueso creciendo hacia el defecto, el cual no se ha llenado completamente y por tanto, el borde de la sección esta aun bien diferenciado. Se observan claramente trabéculas óseas no diferenciadas, con menor cantidad de osteocitos y menor cantidad de vasos sanguíneos.

\section{Discusión}

De acuerdo a las observaciones realizadas se puede concluir que el material poroso de CAp de síntesis seca 
Rodríguez E., Pinzón L., Garzón D., Cabrera L., Bernal C., Zakaria F., Mikán J.
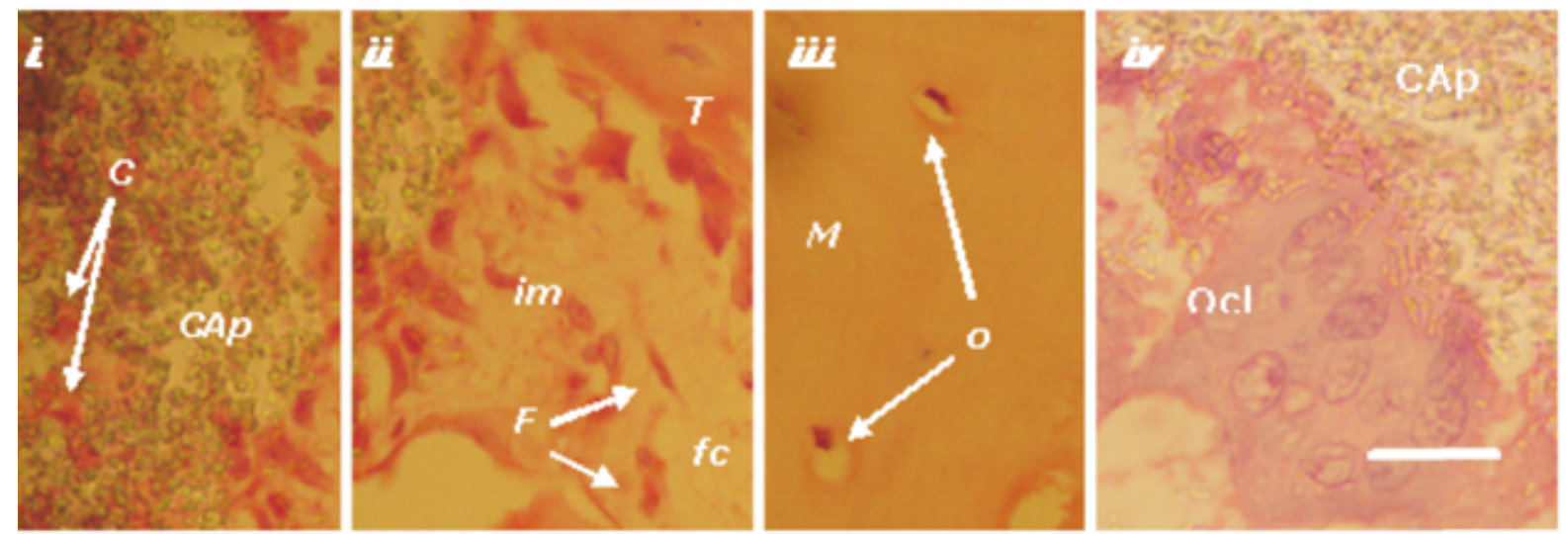

\section{A}
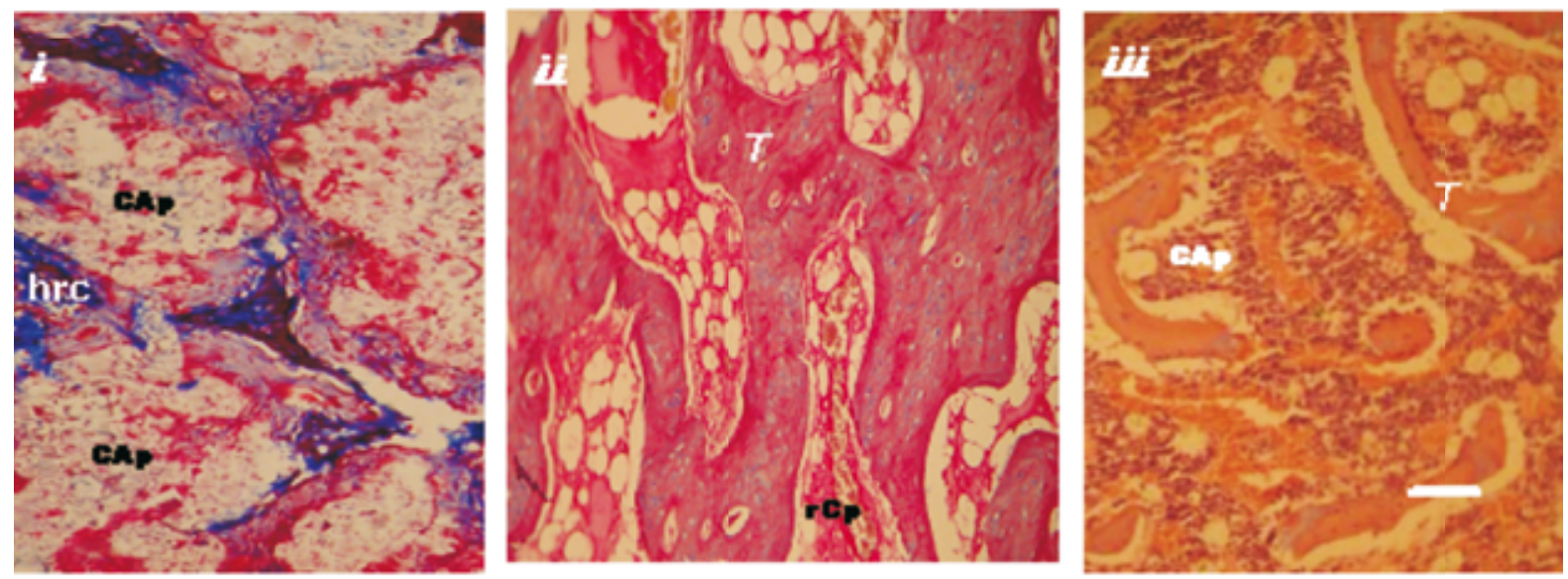

B
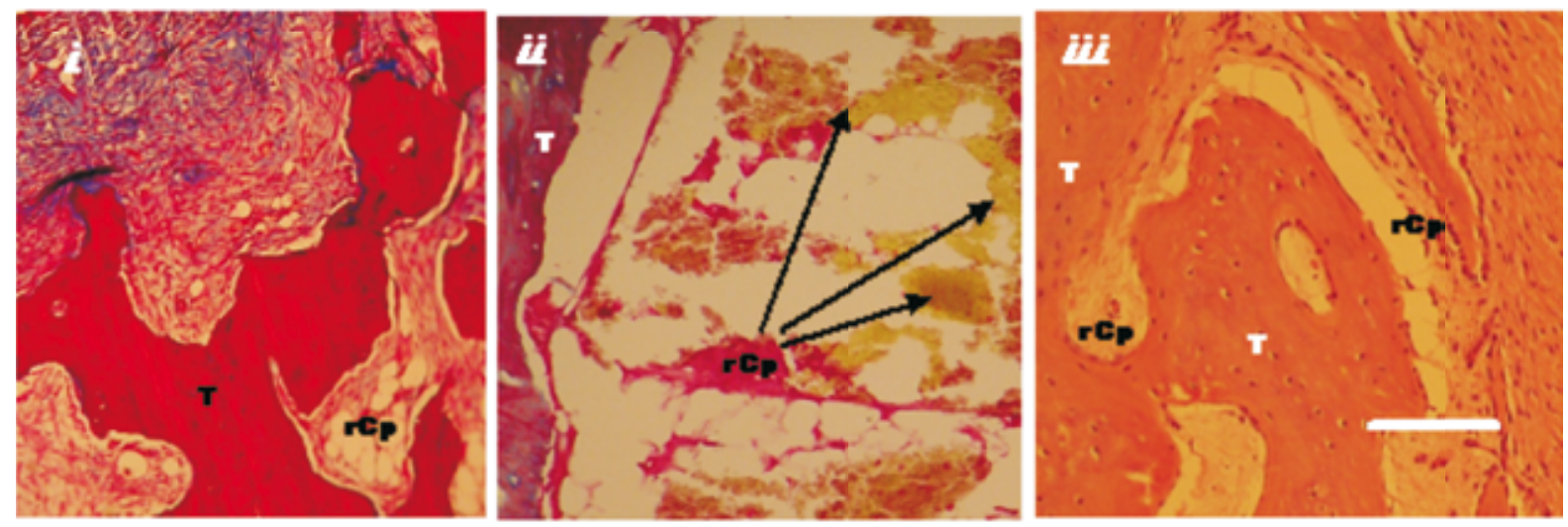

C

FIGURA 7. Análisis microscópico de los cambios en las perforaciones óseas creadas y reemplazadas con CAp. A) Tinción HE de los cortes de los implantes de dos semanas de evolución: (i) interior del defecto cubierto con cristales refringentes de CAp y células (C); (ii) Zona limitante donde se observan fibroblastos $(F)$, fibras colágenas ( $f c)$, infiltrado linfomonocitario (im) y con la formación de trabéculas (T); (iii) Hueso maduro donde se destacan los osteocitos (o) y la matriz (M) y (iv) Detalle de osteoclasto sobre CAp. Barra de 10 micrómetros. B) Cortes mostrando: (i-ii) engrosamiento de las trabéculas $(T)$ que crecen entre los granos CAp y pasan de hueso inmaduro rico en colágeno ( $h r c-a z u l)$ a dos semanas, a trabéculas calcificadas maduras (rojo-azul) a cuatro semanas, mientras CAp es reabsorbido (rCp) con tinción de TM; y (iii) detalle de con tinción H-E gránulos de CAp siendo resorbidos y reemplazados con trabéculas óseas (T) a 4 semanas. Barra de 100 micrómetros. C) Cortes a ocho semanas mostrado: (i-ii) restos de CAp ( $r \mathrm{Cp}$ ) entre trabéculas completamente calcificadas (T) con tinción TM; y (iii) con tinción de H-E. Barra de 100 micrómetros. 
no genera rechazo por parte del organismo después de su implantación subcutánea, ya que en todos los poros del material se encontraron vasos sanguíneos y tejido conectivo inmaduro, del cual se podrían derivar tejidos conectivos como el tejido óseo (21). Es posible que la respuesta inmunitaria observada sea una respuesta celular adaptativa, específica y crónica, considerando la presencia de linfocitos indiferenciados, plasmocitos y macrófagos, los cuales generan células multinucleadas. La presencia de capilares en todos los poros del material es de gran importancia ya que el éxito del implante depende de la llegada de nutrientes, oxigeno y la detoxificación (2).

Las observaciones histológicas evidencian la osteoinducción en piezas de CAp porosas de síntesis seca, solas o embebidas con células de la medula ósea, implantadas en tejido subcutáneo, el cual no esta en contacto con el tejido óseo del porcino. Esto lo indica la presencia de células precursoras, observadas como tejido conectivo inmaduro y que probablemente derivan de células madre mesenquimales presentes en el tejido subcutáneo o que viajaron por el torrente sanguíneo, con capacidad de diferenciarse en células óseas como los osteoblastos (6).

Teniendo en cuenta que los porcinos tratados eran juveniles en crecimiento activo, donde hay extenso desarrollo de adipocitos, los cuales tienen progenitores comunes con las células óseas (células madre mesenquimales), resulta factible que el material implantado no embebido con células de la medula ósea, atraiga y permita el desarrollo de células mesenquimales, ya presente en tejido subcutáneo, en tejido óseo; de manera semejante, la respuesta inmunitaria inicial, permite la invasión desde el torrente sanguíneo de monocitos que se diferencian posteriormente en preosteoclastos, inducidos por los minerales de CAp (19, 22). La actividad de estos osteoclastos podría explicar la resorción y por tanto la disminución de la cantidad de material (22) y la observación de abundante matriz extracelular compuesta en su mayoría de colágeno (probablemente tipo I y sintetizado por osteoblastos).

\section{Análisis de cuantificación}

La comparación temporal de los resultados nos permite observar una disminución progresiva del área ocupada por CAp y un aumento importante de las células mesenquimales en ambas muestras, lo que está a favor del recambio del material de osteosíntesis por tejido de aparente capacidad osteogénica, lo que demostraría una capacidad osteoinductiva de CAp de síntesis seca. En cuanto a los vasos sanguíneos, se observa un aumento en el número de los mismos, especialmente para la octava semana en las muestras control, mientras en los tratamientos el número se mantiene a lo largo del tiempo. Estos resultados nos permiten pensar que el material con células podría generar una mayor biocompatibilidad con el tejido receptor.

La comparación de las muestras control y tratamiento permite determinar que la resorción del material se ve favorecida por el tratamiento previo de CAp con células de la medula ósea. Sin embargo, no es evidente la variación en el número de células mesenquimales en las observaciones histológicas, ya que se observó mayor cantidad de estas en las muestras control en las semanas cuatro y ocho. Esto podría explicarse con la disminución de células precursoras concomitante con el proceso de diferenciación de las mismas a células óseas (preosteoblastos y osteoblastos), lo que estaría a favor de la osteoinducción (23). También se podría explicar por un efecto de resorción ósea, debida a la diferenciación a osteoclastos a partir de progenitores hematopoyéticos que llegan por medio de la vascularización observada.

\section{Cortes de implantes óseos}

La observación del proceso de regeneración del defecto óseo creado mostró que la reparación de tejido hasta las ocho semanas, se llevó a cabo por osificación membranosa. Se observó la presencia de células mesenquimales indiferenciadas y fibroblastos, las cuales probablemente migraron desde el tejido sano contiguo y/o de la circulación sanguínea (24); estas conformaron un enramado de tejido conectivo inmaduro similar al embrionario, para posteriormente diferenciarse a trabéculas óseas jóvenes con matriz osteoide (confluencia de osteoblastos que secretan sustancia eosinofílica), la que luego se calcifica (engrosamiento de las trabéculas en color rojo en la coloración TM). En la octava semana fue aparente una mayor cantidad de trabéculas óseas maduras en las muestras tratamiento, lo que indicaría una mejoría en la osteoconducción relacionada con la presencia del material de CAp (24). Sin embargo, en ambas muestras los defectos no han sido totalmente reparados. Para obtener una mejor evidencia del papel osteoconductivo de CAp poroso, se hace necesario realizar defectos óseos del tamaño crítico, es decir, el tamaño en el cual ya no alcanza a reparación por si sola. 
Las observaciones de los tratamientos con CAp poroso permiten evidenciar que el proceso fisiológico de reparación ósea no se disminuye por la presencia de la cerámica. Por el contrario, esta estaría mejorando el proceso ya que se observó un aumento en el número de vasos sanguíneos y al mayor número de células osteogénicas observadas en los cortes de los tratamientos comparados con las placas control durante el tiempo del experimento. Sin embargo, es necesario realizar estudios similares con un mayor tiempo de observación y como ya se mencionó, con perforaciones de mayor tamaño, donde se evidencie el papel de CAp poroso de síntesis seca en la regeneración ósea de defectos con perdida de hueso significativo.

\section{Agradecimientos}

Los autores agradecen al Ministerio de Ciencia, Tecnología e Innovación de Malasia por la financiación de la investigación 0303-02-SF0010, a SIRIM Berhad y a la Universidad Militar Nueva Granada, Fondo de investigaciones, por la financiación del proyecto MED -2004-004.

\section{Referencias}

1. Nelson E R, Huang Z, Ma T, Lindsey D, Jacobs C, Smith R L et al. New Bone Formation by Murine Osteoprogenitor Cells Cultured on Corticocancellous Allograft Bone. Journal of Orthopaedic Research. 2008;26(12):1660-4.

2. Jabbarzadeh E, Starnes T, Khan Y M, Jiang T, Wirtel A J, Deng M et al. Induction of Angiogenesis in Tissue-Engineered Scaffolds Designed for Bone Repair: A Combined Gene Therapy-Cell Transplantation Approach. Proceeding of the National Academy of Sciences. 2008;105(32):11099-11104.

3. Osathanon T, Linnes M L, Rajachar R M, Ratner B D, Somerman M J, Giachelli C M. Microporous Nanofibrous FibrinBased Scaffolds for Bone Tissue Engineering. Biomaterials. 2008;29:4091-4099.

4. Schönmeyr B H, Wong A K, Li Sen M S, Gewalli F. Treatment of Hydroxyapatite Scaffolds with Fibronectin and Fetal Calf Serum Increases Osteoblast Adhesion and Proliferation in Vitro. Plastic and Reconstructive Surgery. 2008;121(3):751-762.

5. Guo H, Su J, Wei J, Kong H, Liu C. Biocompatibility and Osteogenicity of Degradable Ca-deficient Hydroxyapatite Scaffolds from Calcium Phosphate Cement for Bone Tissue Engineering. Acta Biomaterialia. 2009;5(1):268-278.

6. Taguchi Y, Amizuka N, Nakadate M, Ohnishi H, Fujii N, Oda $\mathrm{K}$ et al. A Histological Evaluation for Guided Bone Regeneration Induced by a Collagenous Membrane. Biomaterials. 2005;26:6158-6166.
7. Ogose A, Kondo N, Umezu H, Hotta T, Kawashima H, Tokunaga $\mathrm{K}$, et al. Histological assessment in grafts of highly purified betatricalcium phosphate (OSferions) in human bones. Biomaterials 2006; 27:1542-1549.

8. Liao S, Watari F, Zhu Y, Uo M, Akasaka T, Wang W et al. The Degradation of the Three Layered Nano-carbonated Hydroxyapatite/Collagen/PLGA Composite Membrane in Vitro. Dental Materials. 2007;23:1120-1128.

9. Li B, Chen X, Guo B, Wang X, Fan H, Zhang X. Fabrication and Cellular Biocompatibility of Porous Carbonated Biphasic Calcium Phosphate Ceramics with a Nanostructure. Acta Biomateralia. 2009;5(1):134-143.

10. Rey C, Collins B, Goehl T, Dickson I, Glimcher M. The Calcified Tissue International. 1989;45:157-164.

11. Rey C, Renugopalakrishnan V, Collins B, Glimcher M. The Calcified Tissue International. 1991;49:251-258.

12. Pountos I, Giannoudis P V. Biology of Mesenchymal Stem Cells. Injury. 2005;36(3):8-12.

13. Diaz L, Villamil M, Bernal C et al. Cultivo de Células del Linaje Ostogénico de Periosteo de Porcino para la Evaluación de un Biomaterial. Revista Med. 2007;15(2):192-206.

14. Zakaria F, Marsad N, Adbul M et al. Characterisation of Carbonated Apatite for Possible Application in Biomedical Implants. Materials Research Innovations. 2009;13(3):309-312.

15. Mikan J, Villamil M, Montes T et al. Porcine Model for Hybrid Material of Carbonated Apatite and Osteoprogenitor Cells. Materials Research Innovations. 2009;13(3):323-326.

16. Zakaria F A, Thevi K J, Abu Bakar S H et al. Preparation of Carbonated Apatite and its Evaluation. Proceedings of the Materials and Processes for Medical Devices Conference. 2005 November 14-16. Pg 43-47. Boston, MA, USA, ASM International, 2006.

17. Oyane A, Onuma K, Ito A, Kim H, Kokubo T, Nakamura T J. Formation and Growth of Clusters in Conventional and New Kinds of Simulated Body Fluids. Journal of Biomedical Material Research. 2003;64:339-348.

18. Revell P A. Histomorphometry of Bone. Journal of Clinical Pathology. 1983;36:1323-1331.

19. Heath J W, Young B. Histologia Funcional. ( $\left.4^{\circ} \mathrm{Ed}\right)$. Harcourt. Madrid: España. 2001.

20. Mikan J F y Oliveros W D. Osteoclastogénesis y Enfermedades Óseas. Revista Med. 2007;15(2):261-270.

21. Badiavas E, Falanga V. Treatment of Chronic Wounds with Bone Marrow-Derived Cells. Archives of Dermatology. 2003;139:510-516.

22. Doi Y, Shibutani T, Moriwaki Y, Kajimoto T, Iwayama Y. Sintered Carbonate Apatites as Bioresorbable Bone Substitutes. Journal of Biomedical Material Research. 1998;39(4):603-610.

23. Suh H, Han D W, Park JC, L D H, Lee W S and Han C D. A Bone Replaceable Artificial Bone Substitute: Osteoinduction by Combining with Bone Inducing Agent. Journal of Artificial Organs. 2001;25(6):459-466.

24. Saad B, Kuboki Y, Welti M, Uhlschmid G, Neuenschwander P, Suter U. Degradable and Highly Porous Polyesterurethane Foam as a New Substrate for Bone Formation. Journal of Artificial Organs. 2000;24(12):939-945. 